\title{
Axial Coordination Site-Turned Surface Confinement, Electron Transfer, and Bio-Electrocatalytic Applications of a Hemin Complex on Graphitic Carbon Nanomaterial-Modified Electrodes
}

Khairunnisa Amreen, ${ }^{\dagger}$ Annamalai Senthil Kumar, ${ }^{* \dagger, t, \delta \odot}$ Veerappan Mani, ${ }^{\S \odot}$ and Sheng-Tung Huang ${ }^{\S} \odot$

${ }^{\dagger}$ Nano and Bioelectrochemistry Research Laboratory, Department of Chemistry, School of Advanced Sciences, and ${ }^{\ddagger}$ Carbon Dioxide Research and Green Technology Centre, Vellore Institute of Technology University, Vellore 632 014, India

${ }^{\S}$ Institute of Biochemical and Biomedical Engineering, National Taipei University of Technology, Taipei 10608, Taiwan, ROC

\section{Supporting Information}

\begin{abstract}
Understanding the relation between the chemical bonding and the electron-transfer (ET) reaction of surfaceconfined hemin (a five-coordinated Fe-porphyrin-with-chlorine complex) is a special interest in the biomimicking studies of heme proteins. Owing to the difficulty in ET function, scanty electrochemical reports of hemin in aqueous solution were reported. It has been noticed that in most of the reported procedures, the sixth axial coordination position of the hemin complex has been unknowingly turned by attaching with water molecules (potential cycling in alkaline conditions or heating), solvents such as ethanol and dimethyl sulfoxide, and nitrogendonating compounds that have helped for the heme ET reaction. In this work, a systematic effort has been taken to

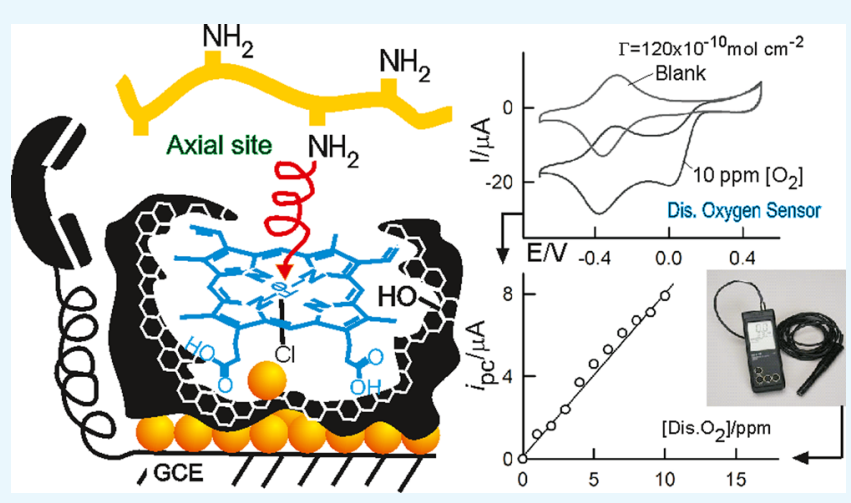
find out the contribution of hemin and its axial bond coordination with $\pi-\pi$ interaction, hydrogen bonding, and hydrophobic binding systems toward the ET reaction. Various graphitic carbons such as graphitized mesoporous carbon (GMC), mesoporous carbon-hydrophilic and hydrophobic units, graphite nanopowder, graphene oxide, single-walled carbon, multiwalled carbon nanotube (MWCNT), and carboxylic acidfunctionalized MWCNT (as a source for $\pi-\pi$ interaction, hydrogen bonding, and hydrophobic environment) along with the amino functional group of chitosan (Chit; as an axial site coordinating system) have been tested by modifying them as a hemin hybrid on a glassy carbon electrode (GCE). In addition, a gold nanoparticle $\left(\mathrm{Au}_{\text {nano }}\right)$ system was combined with the above matrix as a molecular wiring agent, and its role was examined. A highly stable and well-defined redox peak at an apparent formal potential $\left(E^{\mathrm{o} \prime}\right)$ of $-320 \mathrm{mV}$ versus $\mathrm{Ag} / \mathrm{AgCl}$ with the highest surface excess of $120 \times 10^{-10} \mathrm{~mol} \mathrm{~cm}^{-2}$ was noticed with the GCE/ $\mathrm{Au}_{\text {nano }}$-GMC@hemin-Chit hybrid system, wherein all interactive features have been utilized. Omitting any of the individual interactions resulted in either decreased (with $\mathrm{Au}_{\text {nano }}$ ) or nil current response. As applications, efficient bio-electrocatalytic reduction and sensing of dissolved oxygen and hydrogen peroxide have been demonstrated.
\end{abstract}

\section{INTRODUCTION}

Hemin, a five-coordinated Fe-porphyrin-with-chlorine complex (Scheme 1), is a derived active site of the heme-containing proteins and enzymes such as hemoglobin $(\mathrm{Hb})$, cytochrome $C$, horseradish peroxidase, and catalase. ${ }^{1}$ It is produced endogenously in the human body during the turnover of red blood cells (RBCs). ${ }^{2}$ Indeed, it forms inappropriately as a result of vascular (vessels that carry blood) injury or hemolysis (rupture or destruction of RBCs) in the physiological system. ${ }^{3}$ It has been revealed that the endogenously formed hemin helps in intracellular generation of reactive oxygen species (ROS) such as hydrogen peroxide, singlet oxygen, hydroxyl radicals, and superoxide. ${ }^{4}$ At the same time, this hemin has the capacity to interact with the peroxide and oxygen molecules and facilitates their bio-electrocatalytic reduction to water by mediated electron-transfer (ET) reaction mechanism (at specific operating potentials). ${ }^{5}$ Note that meticulous ROS production in human cells assists in energy production ${ }^{6}$ and apoptosis ${ }^{7}$ and supports to combat pathogens. Indeed, abandoned ROS leads to permanent damage of the cell organelles and tissues. ${ }^{8}$ Biomimicking the ET function of the hemin and probing the mysteries of its biological function are a continued research interest. In this regard, fixing hemin as a surface-confined species similar to the natural system is an important step. Unfortunately, there is no clear and systematic information about ET of surface-confined hemin complex covering $\pi-\pi$ and hydrogen bonding and axial ligand coordination, in the literature. The electro-inactive character

Received: February 22, 2018

Accepted: May 7, 2018

Published: May 21, 2018 
Scheme 1. Cartoon for (A-D) Structures of Various Chemically Modified Electrodes and (E-I) Preparation of GCE/Au nano $^{-}$ GMC@Hemin-Chit via Various Intermediate Modified Electrodes

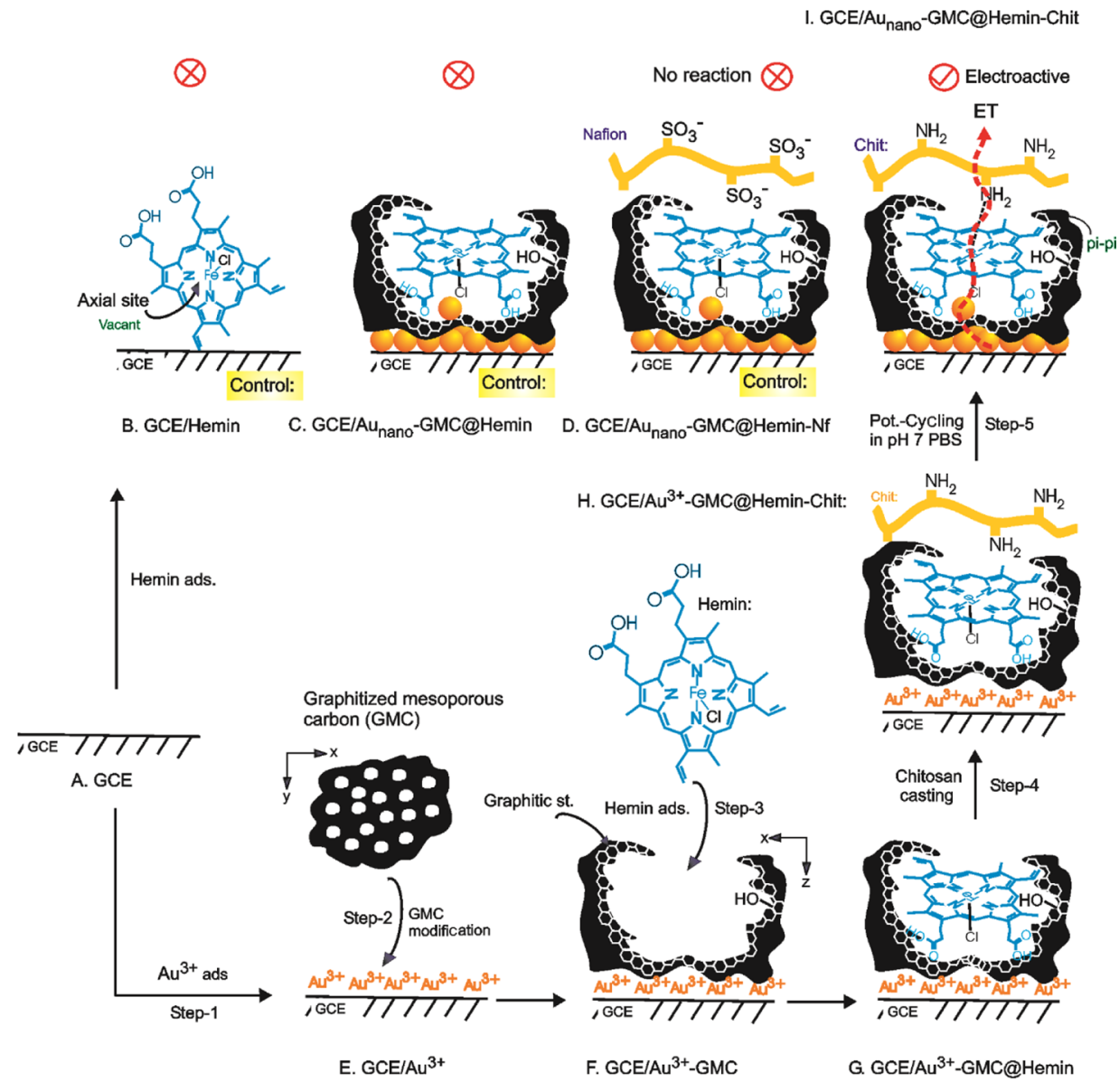

of hemin on solid electrodes is a prime reason for the limitation. Herein, we report a meticulously designed heminconfined carbon nanomaterial (graphitic base)/chitosan (Chit) chemically modified electrode, designated as glassy carbon electrode (GCE)/carbon@hemin-Chit, for an efficient ET and mediated reduction of dissolved oxygen and hydrogen peroxide in a physiological system.

With the aim of biomimetic studies, since 1928, there has been significant interest on the ET feature of hemin (homogenous condition) in organic and semiaqueous mediums. $^{9-12}$ In 1967, Bednarski and Jordan first reported the adsorption and ET study of hemin on the dropping $\mathrm{Hg}$ electrode in $0.1 \mathrm{M} \mathrm{KOH}$ solution and stated that hemin forms a soluble dimer, which undergoes a two-electron reversible reduction to yield a ferroheme monomer (wherein two water molecules are attached on the two axial positions). ${ }^{12}$ Following this, there were several studies on hemin complex with $\mathrm{Hg}$ systems. ${ }^{13,14}$ In 1990, Bianco et al. reported adsorption of hemin on a pyrolytic graphite electrode (PGE) and showed an $\mathrm{ET}$ reaction at $E^{\mathrm{o} \prime} \approx-0.55 \mathrm{~V}$ versus $\mathrm{Ag} / \mathrm{AgCl}$ with a surface excess of $\Gamma_{\text {hemin }}=11 \times 10^{-10} \mathrm{~mol} \mathrm{~cm}{ }^{-2}$ in $\mathrm{pH} 7$ phosphate buffer solution (PBS). ${ }^{15}$ In their preparation procedure, the PGE was simply exposed to hemin solution containing $30 \%$ ethanol/borate buffer of $\mathrm{pH} 11$. It has been claimed that the $\pi-\pi$ interaction between the graphitic sites and hemin is responsible for the adsorption and ET feature. In a similar fashion, hemin was adsorbed on a multiwalled carbon nanotube $(\mathrm{MWCNT})$ via $\pi-\pi$ interaction and showed $E^{\mathrm{o} \prime}=-0.34 \mathrm{~V}$ versus $\mathrm{Ag} / \mathrm{AgCl}$ and $\Gamma_{\text {hemin }}=27 \times 10^{-10} \mathrm{~mol} \mathrm{~cm}{ }^{-2} \cdot{ }^{16}$ Later on, a covalently immobilized hemin on an amino-functionalized MWCNT-modified electrode via 1-ethyl-3-(3dimethylaminopropyl)carbodiimide (EDC) $\left(E^{\mathrm{o} \prime} \approx-0.5 \mathrm{~V}\right.$ vs $\mathrm{Ag} / \mathrm{AgCl}$ in $\mathrm{pH} 1$ buffer) was reported. ${ }^{17}$ Recently, heminimmobilized graphene oxide (GO)- (a hemin $-\mathrm{NaOH}$ solution heated at $70{ }^{\circ} \mathrm{C}$ was used; $E^{\circ \prime}=-0.15 \mathrm{~V}$ vs $\mathrm{Ag} / \mathrm{AgCl} ; \Gamma_{\text {hemin }} \approx$ $\left.1 \times 10^{-10} \mathrm{~mol} \mathrm{~cm}^{-2}\right)^{18}$ and gold nanoparticle-GO (a mixture of ethanolic solution of hemin- $\mathrm{GO}-\mathrm{Au}_{\text {nano }}$ was used; $E^{\mathrm{o} \prime}=$ $-0.4 \mathrm{~V}$ vs $\left.\mathrm{Ag} / \mathrm{AgCl}, \Gamma_{\text {hemin }} \approx 2 \times 10^{-10} \mathrm{~mol} \mathrm{~cm}{ }^{-2}\right)-{ }^{19}$ based chemically modified electrodes were reported in the literature. All of those studies emphasize the $\pi-\pi$ interaction for the ET process. Meanwhile, there were few reports on hemin surfaceconfined gold self-assembled monolayer electrodes utilizing nitrogen-containing biomolecules such as histidine and guanine quadruplex (G4) complexes with $E^{\circ \prime}=-0.22$ to $-0.35 \mathrm{~V}$ versus $\mathrm{Ag} / \mathrm{AgCl}$ and $\Gamma_{\text {hemin }}=0.0016-2.2 \times 10^{-10} \mathrm{~mol} \mathrm{~cm}{ }^{-2}$. These above reports highlight the importance of the planar orientation and axial ligand interactions for the ET activity. ${ }^{20,21}$ In this report, $\pi-\pi$ interaction, axial ligand coordination, and multihydrogen bonding were collectively tuned for the enhanced ET reaction of the hemin on a carbon nanomaterial/Chit-modified electrode system.

Importance of the axial ligand coordination in the ET of hemin was first reported by Richard et al. by studying a series of 29 pentacoordinate hemin derivatives using the cyclic voltammetry $(\mathrm{CV})$ technique in a noncoordinating solvent $\left(\mathrm{CH}_{2} \mathrm{Cl}_{2}\right){ }^{22}$ A linear correlation between the $E^{\mathrm{o} \prime}$ values of the 

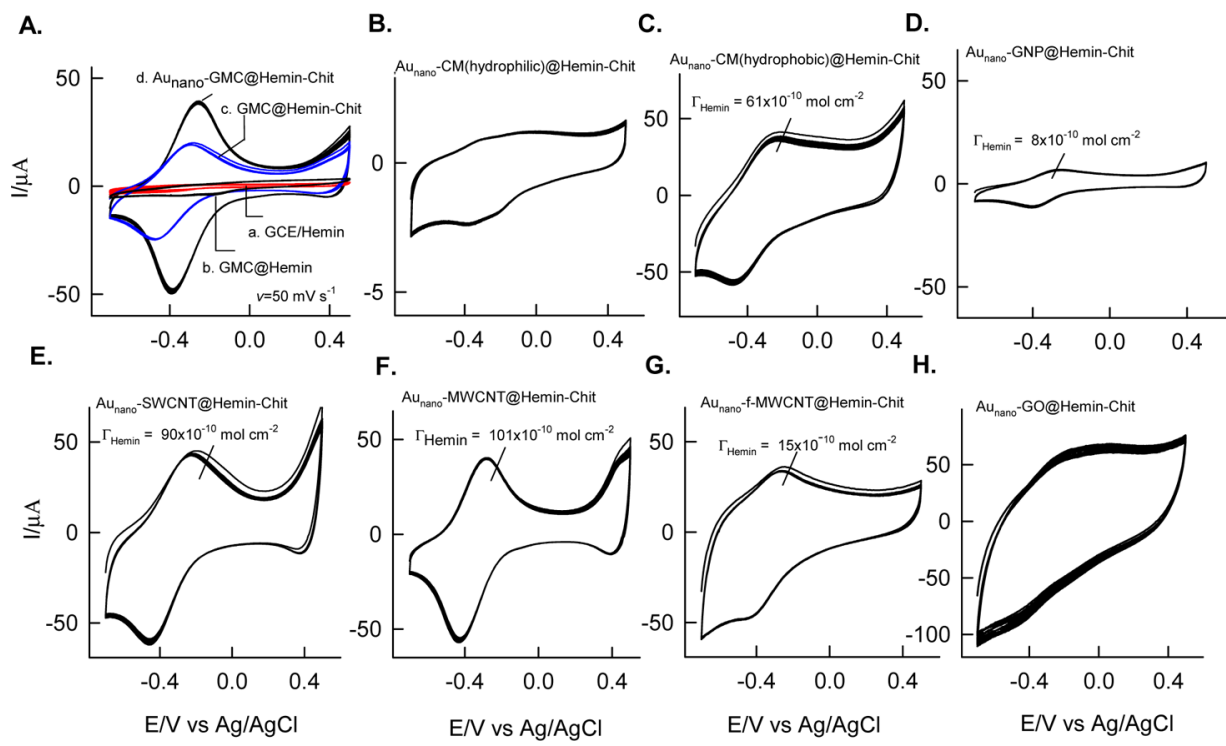

Figure 1. Ten continuous CV responses of (A) (a) GCE/hemin, (b) GCE/GMC@hemin, (c) GCE/GMC@hemin-Chit, and (d) GCE/Au nanoGMC@hemin-Chit and various GCE/ $\mathrm{Au}_{\text {nano }}$-carbon nanomaterial@hemin-Chit systems: (B) mesoporous carbon hydrophilic unit, (C) mesoporous carbon hydrophobic unit, (D) carbon nanofiber, (E) SWCNT, (F) MWCNT, (G) carboxylic-functionalized MWCNT, and (H) GO in $\mathrm{N}_{2}$-purged $\mathrm{pH} 7 \mathrm{PBS}$ at a scan rate of $v=50 \mathrm{mV} \mathrm{s}^{-1}$.

hemin derivatives and $\mathrm{p} K_{\mathrm{a}}$ of the axial ligands had been shown. Further, it was stated that nitrogen- and sulfur-containing solvents such as dimethyl sulfoxide and dimethylformamide are capable of coordinating with hemin (in the sixth position) and assisting the ET feature. ${ }^{22}$ Surprisingly, in many of the previous studies with hemin-surface confined systems, the axial position of the hemin has been unknowingly turned. ${ }^{18,19,21}$ For instance, water molecules attachment in the axial positions by electrochemical treatment in alkaline solution and heating, ${ }^{18}$ and using organic solvent or compounds like ethanol and EDC as a coordinating ligand in the preparation procedure. ${ }^{18,19,21}$ In this report, to understand the role of the sixth vacant axial position of the hemin site in association with other chemical interactions, a systematic effort has been taken by providing a control environment using Chit, graphitic carbon nanomaterials, especially graphitized mesoporous carbon (GMC), and gold nanoparticles to confinement of the hemin complex. The GMC provides not only a graphitic environment for $\pi-\pi$ interaction but also a mesoporous space $(\sim 50 \mathrm{~nm})^{23,24}$ and oxygen functional groups for the entrapment and hydrogen bonding. Similarly, the amino functional group of the Chit helps for the sixth vacant axial position coordination, and gold nanoparticles support as an internal ET linker (wiring). Previously, it has been shown that Chit, a linear polysaccharide-based biopolymer obtained from shrimp cells, ${ }^{23}$ is effective for complexation with the iron site ${ }^{25-27}$ and gold nanoparticles as a linker for the electrical wiring of biomolecules. ${ }^{28-30}$ Several control experiments were carried out utilizing different carbon nanomaterials such as mesoporous carbon (CM)-hydrophobic unit, CMhydrophilic unit, GO, graphite nanoparticles (GNPs), singlewalled carbon nanotube (SWCNT), MWCNT, and carboxylic group-functionalized MWCNT (f-MWCNT) to find the contribution of the $\pi-\pi$ and oxygen functional group influences on the ET feature of the hemin. In addition, owing to its biological relevance, ${ }^{4-8}$ dissolved oxygen and hydrogen peroxide reduction reactions mediated by the surface-confined hemin in a physiological system have been studied as model systems.

\section{RESULTS AND DISCUSSION}

2.1. CV Study of GCE/Au nano - Carbon@Hemin-Chit. Initial experiments were carried out using GMC as a standard system. At first, the hemin complex is adsorbed on a bare GCE surface and subjected to $\mathrm{CV}$ study in $\mathrm{N}_{2}$-purged $\mathrm{pH} 7$ PBS. As can be seen in Figure 1A, curve a, a featureless voltammetric response was noticed. This observation is the same when the hemin is modified on GCE/GMC as GCE/GMC@hemin (Figure 1A, curve b) (Scheme $1 \mathrm{~A}-\mathrm{C}$ ). Note that, even after providing a graphitic environment by GMC, which can support $\pi-\pi$ interaction, there is no specific redox signal for hemin. This is the reason why, in previous reports, hemin surfaceconfined graphene and $\mathrm{GO} /$ gold nanoparticle systems failed to show any marked characteristic redox peak at an apparent electrode potential of $E^{\mathrm{o}^{\prime}}=-0.320 \mathrm{~V}$ versus $\mathrm{Ag} / \mathrm{AgCl}$ in neutral $\mathrm{pH}$ solution, ${ }^{32,33}$ affirming that graphitic interaction alone could not be a prime factor for the ET reaction. Interestingly, when a dilute solution of Chit polymer which contains an amino functional group is coated on GCE/GMC@ hemin, as GCE/GMC@hemin-Chit, a well-defined redox peak at $E^{\mathrm{o} \prime}=-380 \pm 5 \mathrm{mV}$ versus $\mathrm{Ag} / \mathrm{AgCl}$ with a surface coverage $\left(\Gamma_{\text {hemin }}\right)=62 \times 10^{-10} \mathrm{~mol} \mathrm{~cm}^{-2}$ appeared because of the ET of the surface-confined hemin (Figure 1A, curve c). Meanwhile, a $1 \%$ Nafion (Nf) polymer, a characteristic cationic exchange polymer without any amino functional group, is casted on GCE/GMC@hemin, as GCE/GMC@hemin-Nf, and tested (Supporting Information Figure S1). In addition, hemin adsorbed on the Chit-modified electrode, that is, GCE/ Chit@hemin, was also tested (data not included). There is no formation of the redox peak in the previous cases. These observations highlight the important role of the amino functional group along with the graphitic environment for the redox tuning of the hemin. In the literature, the amino group in Chit has been referred to as a good coordinating site. Our group utilized Chit for the complexation with the iron site buried in the pristine MWCNT. ${ }^{26}$ Similarly, Chit-iron(III)modified smectites, ${ }^{34}$ a $\left[\mathrm{Fe}(\mathrm{CN})_{5}\left(\mathrm{NH}_{3}\right)\right]^{3-}$ complex-incorporated Chit hybrid film, ${ }^{35}$ and an $\mathrm{Fe}(\mathrm{III})-$ Chit complex ${ }^{36}$ have 
A.

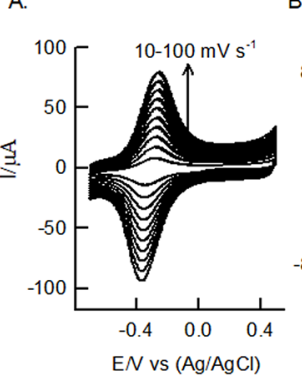

B.

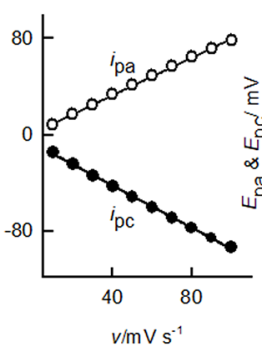

C.

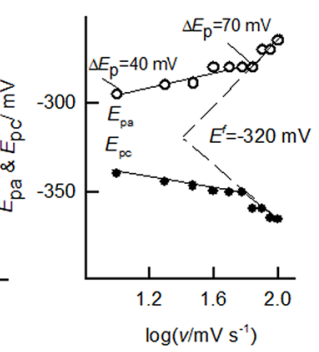

D.

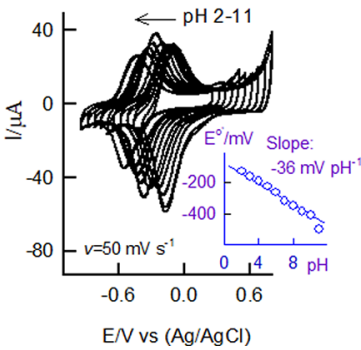

Figure 2. (A) CV response of effect of scan rate $\left(10-160 \mathrm{mV} \mathrm{s}^{-1}\right)$ on $\mathrm{GCE} / \mathrm{Au}_{\text {nano }}-\mathrm{GMC} @$ hemin-Chit in $10 \mathrm{~mL}$ of $\mathrm{N}_{2}$-purged pH $7 \mathrm{PBS}$. Plots of (B) $i_{\mathrm{pc}}$ and $i_{\mathrm{pc}}$ vs $v^{1 / 2}$ and (C) $E_{\mathrm{pc}} \& E_{\mathrm{pa}}$ vs $\log v$. (D) Effect of solution $\mathrm{pH}\left(\mathrm{N}_{2}\right.$-purged) on the CV response of GCE/Au $\mathrm{u}_{\text {nano }}-\mathrm{GMC} @$ hemin-Chit. The inset (D) is a plot of $E^{\mathrm{o} \prime}$ vs $\mathrm{pH}$ for the CV response of the GCE/Au/GMC@hemin-Chit system in different $\mathrm{pH}$ solutions at scan rate of $50 \mathrm{mV}$ $\mathrm{s}^{-1}$.

been reported in the literature utilizing complexation of the amino functional group with the iron site. In this work, it is expected that the amino functional group of Chit is bounded on the sixth vacant position of the hemin (axial bond) and helped the ET process.

With an aim to improve the performance and literature reports based on molecular wiring systems, ${ }^{16,29,30,37-39} \mathrm{Au}_{\text {nano }}$ particles were chosen as a wiring agent and incorporated in the optimal electrode as a GCE/ $\mathrm{Au}_{\text {nano }}$-GMC@hemin-Chit configuration. The preparation procedure was optimized as casting a dilute solution of $\mathrm{Au}^{3+}$ ion on the GCE as the first step followed by other modification procedures. During the electrochemical potential cycling experiment, the $\mathrm{Au}^{3+}$ ion was in situ reduced as $\mathrm{Au}_{\text {nano }}$ particles and molecularly wired in the matrix (Scheme $1 \mathrm{H}, \mathrm{I}){ }^{31}$ Figure $1 \mathrm{~A}$ (curve $\mathrm{d}$ ) shows a typical CV response of $\mathrm{GCE} / \mathrm{Au}_{\text {nano }}-\mathrm{GMC} @$ hemin-Chit, showing the redox peak at $E^{\mathrm{o} \prime}=-320 \pm 2 \mathrm{mV}$ versus $\mathrm{Ag} /$ $\mathrm{AgCl}$ with a 2 -fold enhancement in the $\Gamma_{\text {hemin }}$ value $(120 \times$ $\left.10^{-10} \mathrm{~mol} \mathrm{~cm}{ }^{-2}\right)$. Further, $E^{\circ \prime}$ noticed here is about $70 \mathrm{mV}$ positive than the value obtained without the $\mathrm{Au}_{\text {nano }}$ particlemodified electrode $(-390 \mathrm{mV})$, supporting the molecular wiring within the matrix. The $E^{o \prime}$ value $(-320 \mathrm{mV})$ is matching with previous reports on hemin-modified electrodes, for example, hemin-MWCNT $\left(E^{\circ \prime}=-0.34 \mathrm{~V}\right.$ vs $\left.\mathrm{Ag} / \mathrm{AgCl}\right){ }^{16}$ $\mathrm{Au}_{\text {nano }}-\mathrm{GO}-$ hemin $\left(E^{\mathrm{o}^{\prime}}=-0.4 \mathrm{~V}\right.$ vs $\left.\mathrm{Ag} / \mathrm{AgCl}\right){ }^{19}$ and heminself-assembled gold monolayers via histidine and guanine quadruplex (G4) complexes $\left(E^{\mathrm{o} \prime}=-0.22\right.$ to $-0.3 \mathrm{~V}$ vs $\mathrm{Ag} /$ $\mathrm{AgCl}) .{ }^{20,21}$ The calculated peak-to-peak separation value $\left(\Delta E_{\mathrm{p}}\right)$ is $40 \mathrm{mV}$ at $v=10 \mathrm{mV} \mathrm{s}^{-1}$, indicating a fast ET process. It is noteworthy that the $\Gamma_{\text {hemin }}$ value noticed in this work is the highest compared to the previous literature reports on the hemin-surface-confined system such as PGE@hemin $(11 \times$ $\left.10^{-10} \mathrm{~mol} \mathrm{~cm}{ }^{-2}\right),{ }^{15}$ MWCNT@hemin $\left(27 \times 10^{-10} \mathrm{~mol}\right.$ $\left.\mathrm{cm}^{-2}\right),{ }^{16}$ and N-doped GO@hemin $\left(13 \times 10^{-10} \mathrm{~mol} \mathrm{~cm}^{-2}\right){ }^{39}$ In continuation, $\mathrm{Nf}$ polymer-coated $\mathrm{GCE} / \mathrm{Au}_{\text {nano }}-\mathrm{GMC} @$ hemin (GCE/ $/ \mathrm{Au}_{\text {nano }}$-GMC@hemin-Nf) was also examined for the redox activity (data not enclosed) (Scheme 1D). However, nil redox response was noticed, confirming the specificity of Chit for the axial coordination ET process. On the basis of the results, it has been proposed that $\pi-\pi$ interaction, axial coordination, hydrogen bonding (oxygen and hydrogen functional groups between hemin, GMC, and Chit), and internal linking (wiring) factors have been collectively involved in the effective ET process in this work.

From the CV study of the effect of scan rate $(v)$, it is confirmed that ET of GCE/ $\mathrm{Au}_{\text {nano }}-\mathrm{GMC} @$ hemin-Chit is surface-confined in nature (anodic and cathodic peak currents $i_{\mathrm{pa}}$ and $i_{\mathrm{pc}}$ vs $v$ are linear starting from the origin) (Figure 2A,B). The ratio of the cathodic and anodic peak currents, $i_{\mathrm{pc}} / i_{\mathrm{pa}}$ is found to be nearly unity, obeying the reversible nature of the ET process. The heterogeneous rate constant $k_{\mathrm{s}}$ was calculated from the Laviron's model at condition $\Delta E_{\mathrm{p}}<200 \mathrm{mV}$ using the equation $k_{\mathrm{s}}=m n F v / R T$, where $m$ is a dimensional-less parameter relating to $\Delta E_{\mathrm{p}}$ and transfer coefficient value $(\alpha)$, $n$ is the number of ET $(n=1), v$ is the scan rate, and other symbols have their own significance. ${ }^{40}$ Priorly, the values $E_{\mathrm{pc}}-$ $E^{\mathrm{f}} / E_{\mathrm{pa}}-E^{\mathrm{f}}=1$ and $\Delta E_{\mathrm{p}}=99 \mathrm{mV}$ at $v=100 \mathrm{mV} \mathrm{s}^{-1}$ (Figure 2C) were applied in the Laviron's working plots, ${ }^{40}$ and the $\alpha$ value was calculated as 0.5 . On the basis of the parameters, the $k_{\mathrm{s}}$ value at $v=100 \mathrm{mV} \mathrm{s}^{-1}$ is then calculated as $1.3 \mathrm{~s}^{-1}$. This value is comparable with the values reported for $\mathrm{Hb}$-based surface-confined systems such as $\mathrm{Hb}-\mathrm{MWCNT}-\mathrm{Nf}\left(1.25 \mathrm{~s}^{-1}\right)$, $\mathrm{Hb}-\mathrm{f}-\mathrm{CNT}-\mathrm{CTAB}$ surfactant-Nf $\left(1.25 \mathrm{~s}^{-1}\right), \mathrm{Hb}-$ ionic liquid-MWCNT-CPE $\left(0.84 \mathrm{~s}^{-1}\right)$, and $\mathrm{Hb}-\mathrm{IL}-\mathrm{MWCNT}-$ carbon paste electrode $\left(0.99 \mathrm{~s}^{-1}\right) .{ }^{41-43}$ Further, the redox peak is $\mathrm{pH}$-dependent in nature (Figure 2D). The plot of $E_{\mathrm{pa}}$ versus $\mathrm{pH}$ is linear with a slope of $-36 \mathrm{mV} \mathrm{pH}^{-1}$, indicating the nonNernstian behavior (expected slope $=-58 \mathrm{mV} \mathrm{pH}^{-1}$ ). ${ }^{26}$ Previously, a similar kind of observation was made with several Hb-modified electrodes: Hb-polymer-grafted MWCNT (-42 $\left.\mathrm{mV} \mathrm{pH}^{-1}\right)^{44}$ and $\mathrm{Hb}-\mathrm{CNT}-\mathrm{HA}\left(-38 \mathrm{mV} \mathrm{pH}{ }^{-1}\right)$ systems. ${ }^{45}$ Partial protonation of ligands is the likely reason for this observation. ${ }^{46}$ At this stage, it is difficult to predict the exact molecular orientation of the hemin in this new system. Further, because the modified electrode is complex in nature and the concentration of the immobilized species is at the nanogram level, it is not convenient to use conventional characterization techniques such as nuclear magnetic resonance and mass spectroscopy to identify the active site. On the other hand, from the control experiments and physicochemical characterization studies, the possible structure and orientation of the surface-confined hemin system can be predicted.

The concept of immobilizing hemin is extended to other carbon nanomaterials as well. Figure $1 \mathrm{~B}-\mathrm{H}$ shows the typical $\mathrm{CV}$ responses of the surface-confined hemin systems on various carbons such as CM-hydrophilic unit, CM-hydrophobic unit, GNPs, SWCNT, MWCNT, f-MWCNT, and GO prepared similar to the GCE/ $\mathrm{Au}_{\text {nano }}$-GMC@hemin-Chit case. With respect to the $\Gamma_{\text {hemin }}$ value, the carbon materials were sequenced as follows (ascending order): GO (no graphitic structure; no redox peak response) $\cong \mathrm{CM}$-hydrophilic unit (no graphitic structure; no redox peak response $)<$ GNPs $\left(8 \times 10^{-10} \mathrm{~mol}\right.$ $\left.\mathrm{cm}^{-2}\right)<$ f-MWCNT $\left(15 \times 10^{-10} \mathrm{~mol} \mathrm{~cm} \mathrm{~cm}^{-2}\right)<\mathrm{CM}-$ hydrophobic unit $\left(61 \times 10^{-10} \mathrm{~mol} \mathrm{~cm}^{-2}\right)<\operatorname{SWCNT}(90 \times$ 


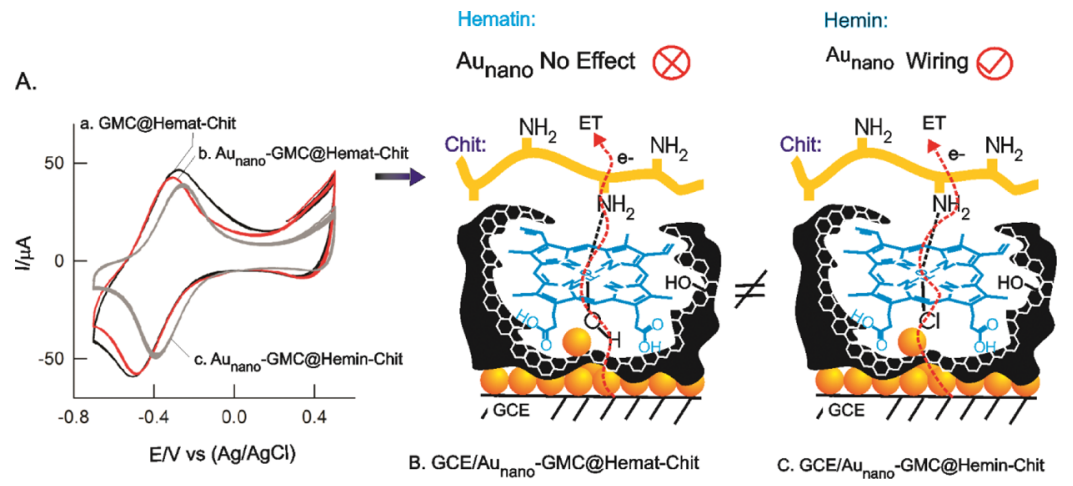

Figure 3. (A) Comparative CV responses of (a) GCE/GMC@hematin-Chit, (b) GCE/Au $\mathrm{unano}_{\text {no }}$ GMC@hematin-Chit, and (c) GCE/Au nanoGMC@hemin-Chit in $\mathrm{N}_{2}$-purged pH 7 PBS at a scan rate of $v=50 \mathrm{mV} \mathrm{s}^{-1}$. (B,C) Comparative cartoons for the hematin- and hemin-modified electrodes with $\mathrm{Au}_{\text {nano }}$ showing unequal ET reaction characteristics.

$\left.10^{-10} \mathrm{~mol} \mathrm{~cm}^{-2}\right)<\operatorname{MWCNT}\left(101 \times 10^{-10} \mathrm{~mol} \mathrm{~cm}^{-2}\right)<\mathrm{GMC}$ $\left(120 \times 10^{-10} \mathrm{~mol} \mathrm{~cm}^{-2}\right)$. Following important conclusions can be derived from the observations: (i) The graphitic structure is necessary. (ii) Comparing hydrophilic and hydrophobic structures, hydrophobic units have positive assistance for ET process. (iii) Oxygen functional groups such as carboxylic and ether in f-MWCNT and GO have a negative effect with the functional group of hemin. Possibly, there may be electrostatic repulsions between the oxygen functional groups (hemin$\left.\mathrm{COOH}, \mathrm{pK} K_{\mathrm{a}} \approx 3.8\right)^{22}$ and hence avoid the communication. Indeed, a fraction of the carbon's oxygen functional groups helped for the hydrogen bond formation. (iv) The MWCNT structure is better than the single-walled structure, which may be due to the highly porous nature. (v) The graphitic structure along with the porous site provided by the GMC is the best option for the stable entrapment of the hemin system. Overall, it is obvious that tuning of $\pi-\pi$ interaction, hydrophobic interaction, hydrogen bonding, and axial ligand coordination is necessary for the effective ET reaction. Partial or incomplete tuning of the interactions may result in either poor or nil ET process. ${ }^{17,18,28,47-49}$ Because of the well-defined redox peak response, highest $\Gamma_{\text {hemin }}$ and low material cost, GMC has been chosen as a model system in this work.

In order to find out the interaction of $\mathrm{Au}_{\text {nano }}$ on the hemin functional group, control experiments were carried out with other forms of hemin derivative, hematin, modified electrodes, that is, GCE/Au $\mathrm{Aun}_{\text {no }}-\mathrm{GMC} @$ hematin-Chit and GCE/GMC@ hematin-Chit (without $\mathrm{Au}_{\text {nano }}$ ). The hematin electrodes were prepared similar to $\mathrm{GCE} / \mathrm{Au}_{\text {nano }}-\mathrm{GMC} @$ hemin-Chit and tested. Figure 3 (curves $\mathrm{a}$ and $\mathrm{b}$ ) shows the typical $\mathrm{CV}$ responses of $\mathrm{GCE} / \mathrm{Au}_{\text {nano }}-\mathrm{GMC} @$ hematin-Chit (curve b) and GCE/GMC@hematin-Chit (curve a) in $\mathrm{N}_{2}$-purged pH 7 PBS at $v=50 \mathrm{mV} \mathrm{s}^{-1}$. Unlike the hemin case with a $50 \%$ increment in the $\Gamma_{\text {hemin }}$ value (Figure 1A, curve c), there is no significant effect of $\mathrm{Au}_{\text {nano }}$ on the redox feature of the hematin (Figure 3, curves $\mathrm{a}$ and $\mathrm{b}$ ). Both $\mathrm{Au}_{\text {nano-modified and }}$ unmodified hematin electrodes showed almost similar redox peaks signals (Figure 3). Note that, both hemin and hematin have the same molecular structure and varies only in the fifth axial ligands, where in, chloride $(\mathrm{Cl})$ with hemin and hydroxide $(\mathrm{OH})$ with hematin (Scheme 1). From these results, it can be revealed that $\mathrm{Au}_{\text {nano }}$ has a positive interaction with the chloride ligand of hemin (likely chemisorption) as $\left\{\mathrm{Fe}-\mathrm{Cl} \cdots \mathrm{Au}_{\text {nano }}\right\}$ (molecular wiring) in turn for the enhanced communication.

2.2. Physicochemical Characterizations. Transmission electron microscopy (TEM) images of $\mathrm{Au}_{\text {nano }}$-GMC@hemin-
Chit and GMC@Chit systems are shown in Figure 4. There is no marked change in the structural feature, except for black
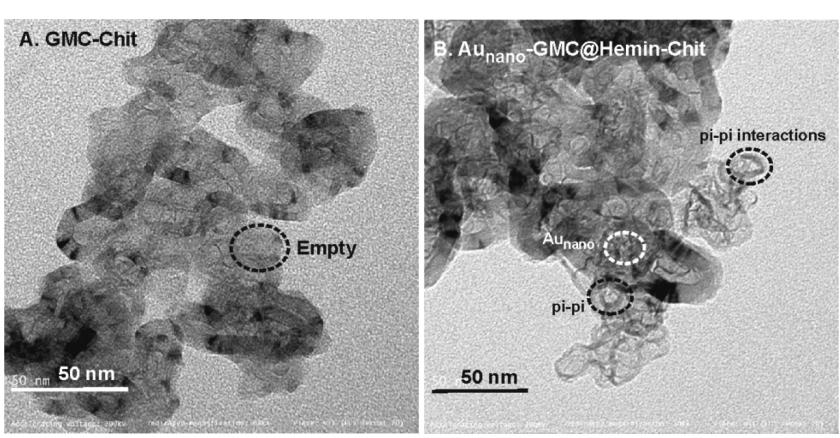

Figure 4. TEM images of GMC-Chit (A) and $A u_{\text {nano }}-$ GMC@ hemin-Chit (B) systems.

shades on the graphitic structure and fine dots of $\sim 20-40 \mathrm{~nm}$ in size with $\mathrm{Au}_{\text {nano }}-\mathrm{GMC} @$ hemin-Chit. These preliminary observations may support $\pi-\pi$ interaction between the hemin and the graphitic structure of GMC and the presence of some nanoparticles in the matrix. Extended experiment with TEMenergy-dispersive X-ray spectrometry (EDXS) showed signals corresponding to $\mathrm{Cu}$ (because of the copper grid), $\mathrm{Au}$, and $\mathrm{Fe}$ atoms (Supporting Information Figure S2). This observation confirms the existence of hemin-Fe and Au systems on the modified electrode. Supporting Information Figure S3 shows comparative Raman spectroscopic responses of Au/GMC@ hemin-Chit and unmodified GMC displaying specific D and G bands corresponding to the graphitic (hexagonal $\mathrm{sp}^{2}$ carbons) and disordered structure ( $\mathrm{sp}^{3}$ carbons), respectively. ${ }^{46}$ The calculated intensity ratio between $\mathrm{D}$ and $\mathrm{G}$ bands, $I_{\mathrm{D}} / I_{\mathrm{G}}$, for Au/GMC@hemin-Chit (0.214) is less than that for the unmodified GMC (0.2707). These data indicate an improvement in the graphitic structure of GMC by the hemin surface confinement through $\pi-\pi$ interaction. Although the porphyrin rings have $\pi$ bonds, because of the improper orientation, they may not be completely aligned on the six-membered $\pi$ structure of the GMC-graphitic units. On the other hand, the alkene tail in hemin is expected to have positive $\pi-\pi$ interaction with the graphitic structure (Scheme 1). UV-vis spectroscopic characterization was also used for the structural identification in this work. For that, respective GCE-modified electrode was sonicated with $500 \mu \mathrm{L}$ of PBS and filtered with a microsyringe. Figure $5 \mathrm{~A}$ shows a typical $\mathrm{UV}-$ vis response of 
A.

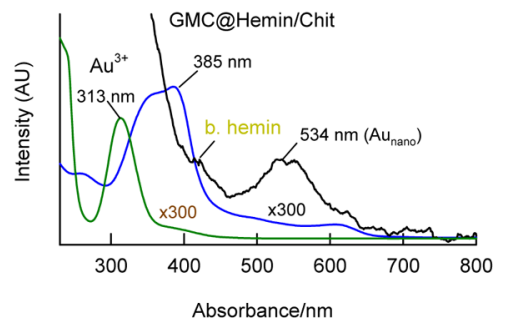

B.

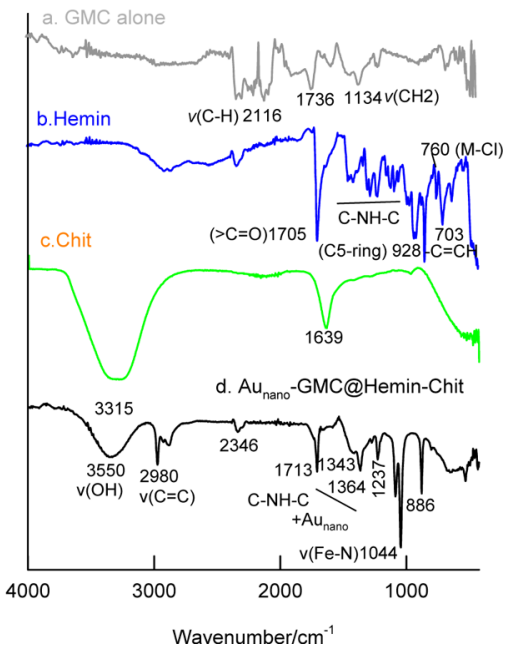

Figure 5. (A) UV-vis and (B) FTIR spectroscopic analysis results of $\mathrm{Au}_{\text {nano }}-\mathrm{GMC} @$ hemin-Chit with various control samples.
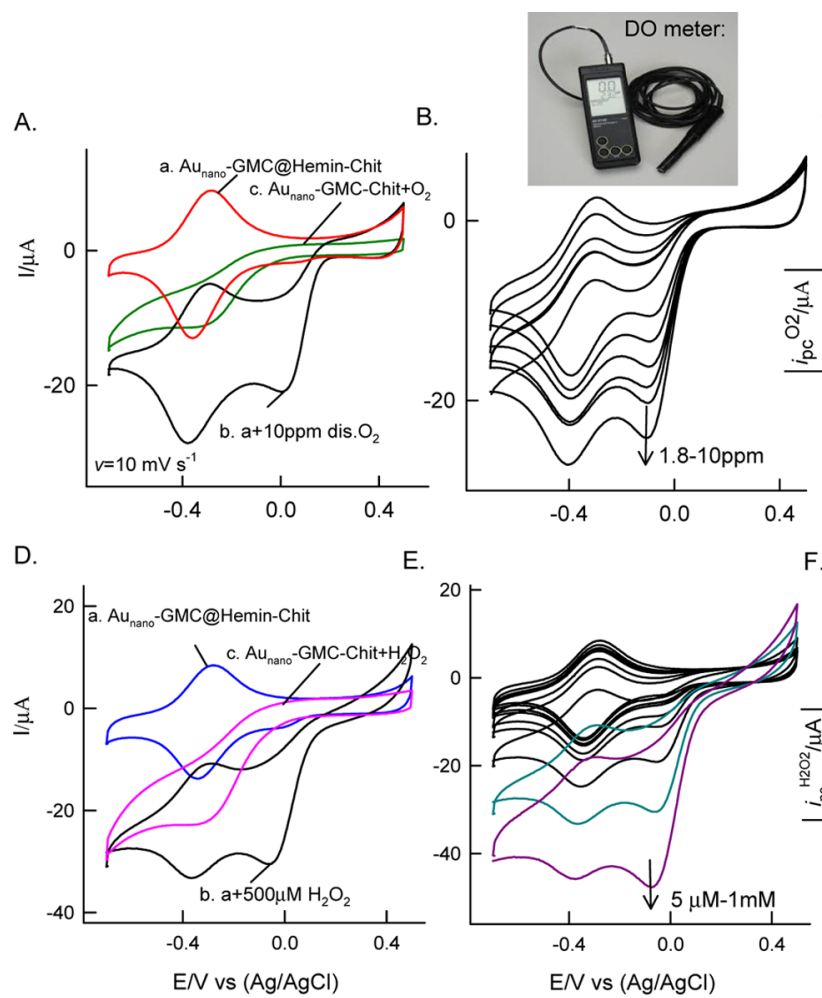

C.

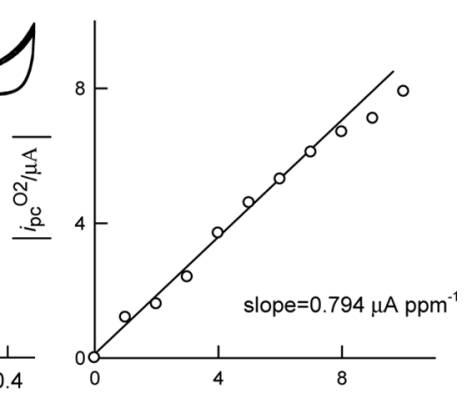

F. $\quad\left[\right.$ dis. $\left.\mathrm{O}_{2}\right] / \mathrm{ppm}$

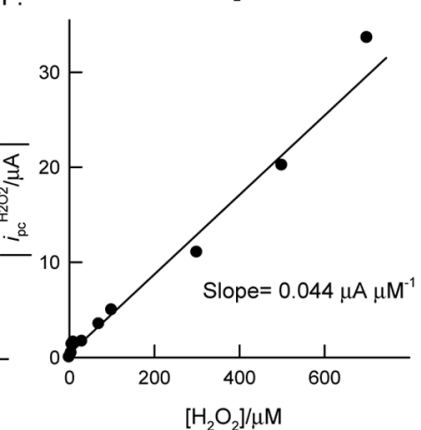

Figure 6. (A) Comparative CV responses of GCE/ $\mathrm{Au}_{\text {nano }}-\mathrm{GMC} @$ hemin-Chit without (a) and with (b) dissolved oxygen (10 ppm) in pH 7 PBS. Curve $\mathrm{c}$ is GCE/ $\mathrm{Au}_{\text {nano }}-\mathrm{GMC}-\mathrm{Chit}$ in dissolved oxygen $(10 \mathrm{ppm})$ in pH 7 PBS. (B) CV responses of GCE/Au nano $^{-G M C @ h e m i n-C h i t ~ w i t h ~}$ increasing concentration of $\mathrm{DO}$ at $v=10 \mathrm{mV} \mathrm{s}^{-1}$ and a photograph of the DO meter. (C) Corresponding calibration plot. (D) Comparative CV responses of GCE/ $\mathrm{Au}_{\text {nano }}-\mathrm{GMC} @$ hemin-Chit without (a) with and (b) $\mathrm{H}_{2} \mathrm{O}_{2}$ in pH 7 PBS. Curve c is GCE/Au $/ \mathrm{unn}_{\text {nano }}-\mathrm{GMC}_{\mathrm{C}} \mathrm{Chit}$ in $\mathrm{H}_{2} \mathrm{O}_{2}$. (E) CV responses of GCE/ $/ \mathrm{Au}_{\text {nano }}-\mathrm{GMC} @$ hemin-Chit with increasing $\mathrm{H}_{2} \mathrm{O}_{2}$ concentrations at $v=10 \mathrm{mV} \mathrm{s}^{-1}$. (F) Corresponding calibration plot.

$\mathrm{Au}_{\text {nano }}-\mathrm{GMC} @$ hemin-Chit, hemin, and $\mathrm{Au}^{3+}$ solution (precursor). Specific absorption signals at $\lambda_{\max } \sim 405$ and $534 \mathrm{~nm}$ were noticed. Compared with the control hemin and $\mathrm{Au}^{3+}$ solution and the data from the literature related to hemin-GO hybrid $\left(\lambda_{\max }=413 \mathrm{~nm}\right)^{28}$ and $\mathrm{Au}_{\text {nano }}\left(\lambda_{\max }=520-535 \mathrm{~nm} ; 20-\right.$ $70 \mathrm{~nm}$-sized particles), ${ }^{50}$ the UV-vis signals can be identified as hemin (hybrid) and $\mathrm{Au}_{\text {nano }}$ particles, respectively. Figure $5 \mathrm{~B}$ shows comparative Fourier transform infrared (FTIR) $/ \mathrm{KBr}$ responses of various modified electrodes prepared by pealing the layer of the modified electrode and combined with $\mathrm{KBr}$.
The $\mathrm{Au}_{\text {nano }}-\mathrm{GMC} @$ hemin-Chit system showed specific IR signals at $3550(\nu \mathrm{OH}), 2980(\nu \mathrm{C}=\mathrm{C}), 2356(\nu \mathrm{C}-\mathrm{H}), 1713$ $(\nu \mathrm{C}=\mathrm{O}), 1237-1343\left(\nu \mathrm{C}-\mathrm{NH}-\mathrm{C}\right.$ and $\left.\mathrm{Au}_{\text {nano }}\right), 886(\nu \mathrm{C} 5-$ ring), and $717(\nu-\mathrm{C}=\mathrm{CH}) \mathrm{cm}^{-1}$ for various characteristic functional groups along with a specific intense signal at 1044 $\mathrm{cm}^{-1}$ due to the $\mathrm{Fe}-\mathrm{N}$ stretching, selectively confirming amino group complexation with the axial position of the hemin-Fe site. ${ }^{51}$ These characteristic IR signals (except the $\mathrm{Fe}-\mathrm{N}$ stretching) are found to be slightly shifted with respect to the signals of the corresponding control samples: GMC (3450, 
2116, 1736, and $\left.1134 \mathrm{~cm}^{-1}\right)$, hemin (2994, 1705, 1200-1390, 928, and $708 \mathrm{~cm}^{-1}$ ), and Chit (3315 and $\left.1639 \mathrm{~cm}^{-1}\right) .^{31,52,53}$ The information supports the existence of various functional group interactions such as $\pi-\pi$, hydrophilic, and hydrogen bonding within the new chemically modified electrode.

2.3. Bio-Electrocatalytic Reduction of Dissolved Oxygen and Hydrogen Peroxide. Figure 6A shows the $\mathrm{CV}$ response of GCE/ $/ \mathrm{Au}_{\text {nano }}$-GMC@hemin-Chit with (10 ppm) and without oxygen gas saturation in $\mathrm{pH} 7 \mathrm{PBS}$ at $v=10 \mathrm{mV}$ $\mathrm{s}^{-1}$. A $\mathrm{N}_{2}$ gas-purged $\mathrm{pH} 7 \mathrm{PBS}$ was used as an electrolyte. A well-defined oxygen reduction signal at an onset potential, 0.25 $\mathrm{V}$ versus $\mathrm{Ag} / \mathrm{AgCl}$ with peak current maximums at 0 and -0.38 $\mathrm{V}$ versus $\mathrm{Ag} / \mathrm{AgCl}$, where the hemin redox peak exists, was noticed. A control experiment with a hemin unmodified electrode, $\mathrm{GCE} / \mathrm{Au}_{\text {nano }}-\mathrm{GMC}-\mathrm{Chit}$ showed a reduction signal about $300 \mathrm{mV}$ higher negative potential and about twice lesser in the peak current value than that of the optimal electrode. This observation denotes the hemin redox-mediated reduction of the dissolved oxygen. A pre-reduction peak at about $0 \mathrm{~V}$ versus $\mathrm{Ag} / \mathrm{AgCl}$ noticed with the optimal working electrode is due to immobilization of the hemin at energetically different surfaces such as pores and valleys/asperities of the GMC and its interaction with analytes. ${ }^{43}$ Presumably, hemin trapped at the pores of the GMC, which provide significant $\pi-\pi$ and hydrogen bonding, is responsible for the low-potential peak observation in this work. Figure $6 \mathrm{~B}$ shows the effect of dissolved oxygen concentration on the mediated oxygen reduction current signals. The dissolved oxygen concentration was measured discreetly by a DO meter (the inset of Figure $6 \mathrm{~B})$. A systematic increment in the peak current against the increase in the dissolved oxygen concentration was noticed. The plot of peak current versus dissolved oxygen concentration was linear in a range of $0-8 \mathrm{ppm}$ with a current sensitivity value of $0.794 \mu \mathrm{A} \mathrm{ppm}^{-1}$ (Figure $6 \mathrm{C}$ ). This result highlights the potential use of the new system for dissolved oxygen sensor development.

In addition, electrocatalytic reduction of hydrogen peroxide was also demonstrated with this new hemin-modified electrode system, as in Figure 6D. The $\mathrm{H}_{2} \mathrm{O}_{2}$ reduction signal was noticed at an onset potential of $-0.38 \mathrm{~V}$ versus $\mathrm{Ag} / \mathrm{AgCl}$ with peak maximums at -0.05 and $-0.4 \mathrm{~V}$, similar to the case of the oxygen reduction reaction, due to the mediated reduction by the surface-confined hemin sites. The plot of the reduction peak current signal $\left(i_{\mathrm{pc}}^{\mathrm{H}_{2} \mathrm{O}_{2}}\right)$ versus concentration of $\mathrm{H}_{2} \mathrm{O}_{2}$ is linear in a window $5 \mu \mathrm{M}-1 \mathrm{mM}$ with a current sensitivity value of $0.044 \mu \mathrm{A} \mu \mathrm{M}^{-1}$. With an aim to extend to electroanalytical assays, amperometric $i-t$ analysis of $\mathrm{H}_{2} \mathrm{O}_{2}$ at an applied potential of $0 \mathrm{~V}$ versus $\mathrm{Ag} / \mathrm{AgCl}$ in $\mathrm{N}_{2}$-purged $\mathrm{pH} 7 \mathrm{PBS}$ was also performed by spiking $25 \mu \mathrm{M} \mathrm{H}_{2} \mathrm{O}_{2}$ in a stirred electrolyte solution (Supporting Information Figure S4A). A regular increase in the current signals against the $\mathrm{H}_{2} \mathrm{O}_{2}$ spikes was noticed. The calibration plot of baseline-corrected current signals versus $\left[\mathrm{H}_{2} \mathrm{O}_{2}\right]$ was linear in the range $0-250 \mu \mathrm{M}$ with a relative standard deviation of $3.1 \%(\mathrm{~S} / \mathrm{N}=3)$ (Figure $\mathrm{S} 4 \mathrm{~B}$ ). The calculated detection limit was $6.8 \mu \mathrm{M}$. The analytical results are comparable with the previous literature reports on Hb-based chemically modified electrodes, wherein the detection limit value is in a range of $4-45 \mu \mathrm{M}^{46,54,55}$ In addition, the effect of interferences from various biochemicals such as nitrite $\left(\mathrm{NO}_{2}^{-}\right)$, nitrate $\left(\mathrm{NO}_{3}^{-}\right)$, glucose $(\mathrm{Glu})$, uric acid (UA), ascorbic acid (AA), xanthine (Xan), hypoxanthine (hyp), cysteine $(\mathrm{CysH})$, and dopamine (DP) on the detection of 50 $\mu \mathrm{M} \mathrm{H} \mathrm{H}_{2} \mathrm{O}_{2}$ at an applied potential of $0 \mathrm{~V}$ was analyzed (Supporting Information Figure S4C). There is no significant alteration in the reduction current signals upon spiking the aforementioned interfering biochemicals. This observation indicates the selective $\mathrm{H}_{2} \mathrm{O}_{2}$ electrochemical interaction and reduction similar to the heme-based protein/enzymatic systems. GCE/ $\mathrm{Au}_{\text {nano }}-\mathrm{GMC} @$ hemin-Chit is found to be stable at room temperature for 30 days and beyond (Supporting Information Figure S5), unlike the enzymatic systems, which have poor stability.

\section{CONCLUSIONS}

Highly redox active hemin-complex surface-confined carbon nanomaterial/Chit/ $\mathrm{Au}_{\text {nano }}$ chemically modified electrodes have been prepared by a simple drop-casting technique within $18 \pm$ $2 \mathrm{~min}$. Cyclic voltammetric investigation of the modified electrode showed a well-defined redox peak at $E^{\mathrm{o} \prime}=-320 \pm 2$ $\mathrm{mV}$ versus $\mathrm{Ag} / \mathrm{AgCl}$ with peak-to-peak separation and surface excess values of $40 \mathrm{mV}\left(10 \mathrm{mV} \mathrm{s}^{-1}\right)$ and $120 \times 10^{-10} \mathrm{~mol} \mathrm{~cm}^{-2}$, respectively, in $\mathrm{N}_{2}$ gas-purged $\mathrm{pH} 7$ PBS because of the facile ET behavior of the iron site in the hemin. Control experiments with the absence of Chit and graphitic carbon nanomaterial resulted in nil redox peak response. The new hemin-modified electrode was subjected to several physicochemical characterization studies using TEM, EDXS, Raman spectroscopy, UVvis, and FTIR. The collective results revealed that the axial coordination bonding of amino functional groups of the Chit with sixth vacant site of the hemin is a key step for the ET process of the hemin-surface-confined carbon nanomaterial systems. Incorporating gold nanoparticles in the matrix improved the ET function through molecular wirings. As an electrochemical application, electrocatalytic reductions of dissolved oxygen and hydrogen peroxide in $\mathrm{N}_{2}$-purged $\mathrm{pH} 7$ PBS have been demonstrated. The new modified electrode showed about $300 \mathrm{mV}$ reduction in the overpotential and two times increment in the reduction peak current signals over the respective unmodified electrode, $\mathrm{GCE} / \mathrm{Au}_{\text {nano }}-\mathrm{GMC}-\mathrm{Chit}$. Extension of the new system toward sensor applications of dissolved oxygen and $\mathrm{H}_{2} \mathrm{O}_{2}$ without interference from common biochemicals was also demonstrated. Unlike the enzymatic systems, the hemin surface-confined carbon nanomaterial system showed redox stability over 30 days at room temperature.

\section{EXPERIMENTAL SECTION}

4.1. Chemicals and Reagents. Lyophilized hemin from Bovine (purity > 90\%), GMC (purity > 99.95\%, <50 nm pore size), GO-ethanol dispersed stock solution (GO, $5 \mathrm{mg} \mathrm{mL}^{-1}$, $\sim 80 \%$ carbon basis, flake size-0.5-2.0 $\mu \mathrm{m}$, thickness-0.6$1.2 \mathrm{~nm}$, purity-99\%), mesoporous carbon-hydrophilic core (CM, 99.95\% pure; particle size 5-50 $\mu \mathrm{m}$ ) and mesoporous carbon-hydrophobic core (99.95\% pure; particle size 5-50 $\mu \mathrm{m}$ ), carboxylic acid-functionalized MWCNT (f-MWCNT; $\sim 90 \%$ pure, size 7-15 $\mathrm{nm} \times 0.5-10 \mathrm{~mm})$, SWCNT $(\sim 70 \%$ pure on carbon basis, $0.7-1.1 \mathrm{~nm}$ diameter), and Chit were obtained from Sigma-Aldrich, USA. Standard gold solution (1000 $\mathrm{mg} \mathrm{L}^{-1}$ ) was purchased from SISCO Research Laboratories, India. Other basic chemicals of analytical grade were used without any purification. Nitrogen-purged $(15 \mathrm{~min})$ PBS $\left(\mathrm{N}_{2}\right.$ PBS) of ionic strength $0.1 \mathrm{M}, \mathrm{pH} 7$ was used as a supporting electrolyte. Screen-printed carbon electrodes (SPCEs) were purchased from Zensor R\&D, Taiwan. 
4.2. Apparatus. Electrochemical experiments were carried out using a portable Biologic (USA) instrument with a threeelectrode system comprising hemin chemically modified GCE (GCE/GMC@hemin-Chit) as a working electrode (0.0707 $\mathrm{cm}^{2}$ ), platinum as a counter electrode, and $\mathrm{Ag} / \mathrm{AgCl}$ with $3 \mathrm{M}$ $\mathrm{KCl}$ as a reference electrode with a $10 \mathrm{~mL}$ working volume of $\mathrm{N}_{2}$-purged $\mathrm{pH} 7 \mathrm{PBS}$. Raman spectroscopy analyses were carried out using AZILTRON, PRO 532, (USA) with a $532 \mathrm{~nm}$ laser excitation source. UV-vis analysis was done by using a UV-vis NIR spectrophotometer, JASCO V-670, Japan. FTIR analysis was done with a JASCO 4100 spectrophotometer by $\mathrm{KBr}$ method. A portable dissolved oxygen meter (HI9142) from Hanna Instruments, USA, was used to measure the dissolved oxygen concentration.

4.3. Fabrication of a Hemin Chemically Modified Electrode. First, the GCE ( $3 \mathrm{~mm}$ in diameter) was subjected to a series of chemical, mechanical, and electrochemical cleaning procedures, as reported in the literature. ${ }^{26}$ For the preparation of $\mathrm{GCE} / \mathrm{Au}_{\text {nano }}-\mathrm{GMC} @$ hemin-Chit, the clean surface of GCE was first casted with $\mathrm{Au}^{3+}$ solution $(5 \mu \mathrm{L} ; 1000$ ppm), followed by drying at room temperature for $2 \pm 1 \mathrm{~min}$. Then, $5 \mu \mathrm{L}$ of GMC or other carbon nanomaterial-ethanol suspension $\left(2 \mathrm{mg} \mathrm{mL}^{-1}\right)$ was casted and air-dried $(2 \pm 1 \mathrm{~min})$. Following this, $5 \mu \mathrm{L}$ of hemin $-\mathrm{NaOH}(0.1 \mathrm{M})$ solution $(2 \mathrm{mg}$ $\mathrm{mL}^{-1}$ ) was dropped on the surface of the above modified electrode $\left(\mathrm{GCE} / \mathrm{Au}_{\mathrm{nano}}-\mathrm{GMC}\right)$ and left to dry in an incubator $\left(40 \pm 2{ }^{\circ} \mathrm{C}\right)$ for $5 \pm 1 \mathrm{~min}$. As a last step, $5 \mu \mathrm{L}$ of $0.5 \%$ Chitacetic acid solution was overlayer-coated and air-dried for $2 \pm 1$ min. In total, within $18 \pm 2 \mathrm{~min}$, the modified electrode can be prepared. The modified electrode was potential-cycled in $\mathrm{pH} 7$ $\mathrm{PBS}$ at a window -0.8 to $0.4 \mathrm{~V}$ versus $\mathrm{Ag} / \mathrm{AgCl}$ for 20 scans at $v=50 \mathrm{mV} \mathrm{s}^{-1}$ (Scheme 1). During this process, the $\mathrm{Au}^{3+}$ ions were in situ reduced as Au nanoparticles and stabilized by the amino functional group of Chit in the modified electrodes (Scheme 1H,I). ${ }^{31}$

For Raman spectroscopic characterization, SPCE-coated GMC and $\mathrm{Au}_{\text {nano }}-\mathrm{GMC} @$ hemin-Chit were used. UV-vis spectroscopy measurements were carried out by stripping out the hemin site from the GCE-modified electrode by sonicating the electrode with $500 \mu \mathrm{L}$ of $\mathrm{pH} 7$ PBS followed by microfiltration. To perform a typical FTIR characterization, respective GCE-modified electrodes were peeled off with a doctor's syringe needle $(1 \mathrm{~mm} \times 4 \mathrm{~cm})$, mixed with $\mathrm{KBr}$ as a pellet, and subjected to the analysis. Electrocatalytic reduction of dissolved oxygen and $\mathrm{H}_{2} \mathrm{O}_{2}$ was carried out by exposing $\mathrm{GCE} / \mathrm{Au}_{\text {nano }}-\mathrm{GMC} @$ hemin-Chit to saturated DO (10 ppm, measured by a standard DO meter) taken in $\mathrm{N}_{2}$-purged $\mathrm{pH} 7$ PBS and $500 \mu \mathrm{M} \mathrm{H}_{2} \mathrm{O}_{2}$.

\section{ASSOCIATED CONTENT}

\section{S Supporting Information}

The Supporting Information is available free of charge on the ACS Publications website at DOI: 10.1021/acsomega.8b00322.

Control CV response of Nf overlayer-coated GCE/ $\mathrm{Au}_{\text {nano }}$-GMC@hemin, TEM-EDXS analysis result of $\mathrm{GCE} / \mathrm{Au}_{\text {nano }}$-GMC@hemin-Chit, comparative Raman spectroscopy responses of GMC and $\mathrm{GCE} / \mathrm{Au}_{\text {nano }}-$ GMC@hemin-Chit, amperometric $i-t$ responses of $\mathrm{GCE} / \mathrm{Au}_{\text {nano }}-\mathrm{GMC} @$ hemin-Chit with its control (GCE/ $\left.\mathrm{Au}_{\text {nano }}-\mathrm{GMC}-\mathrm{Chit}\right)$ for the detection of continuous spikes of $25 \mu \mathrm{M} \mathrm{H}_{2} \mathrm{O}_{2}$, calibration plot and interference effect in $\mathrm{N}_{2}$-purged $\mathrm{pH} 7 \mathrm{PBS}$, and comparative stability $\mathrm{CV}$ response of $\mathrm{GCE} / \mathrm{Au}_{\text {nano }}-$ GMC@hemin-Chit (PDF)

\section{AUTHOR INFORMATION}

\section{Corresponding Author}

*E-mail: askumarchem@yahoo.com, askumar@vit.ac.in. Phone: +91-416-2202754 (A.S.K.).

ORCID $\odot$

Annamalai Senthil Kumar: 0000-0001-8800-4038

Veerappan Mani: 0000-0002-0756-7398

Sheng-Tung Huang: 0000-0003-0214-6436

Notes

The authors declare no competing financial interest.

\section{ACKNOWLEDGMENTS}

The authors acknowledge the Department of Science and Technology-Science and Engineering Research Board (DSTSERB-EMR/2016/002818) Scheme. K.A. thanks the Council of Scientific and Industrial Research for the award of her senior research fellowship (09/844(0037)/2016 EMR-I). A.S.K. acknowledges National Taipei University of Technology for the support of distinguished visiting professor program.

\section{REFERENCES}

(1) Meisenberg, G.; Simmons, W. Principles of Medicinal Biochemistry; Elsevier, 2011.

(2) Gottlieb, Y.; Topaz, O.; Cohen, L. A.; Yakov, L. D.; Haber, T.; Morgenstern, A.; Weiss, A.; Berman, K. C.; Fibach, E.; Meyron-Holtz, E. G. Physiologically Aged Red Blood Cells Undergo Erythrophagocytosis in Vivo But Not in Vitro. Haematologica 2012, 97, 994-1002.

(3) Liu, S. C.; Zhai, S.; Palek, J. Detection of Hemin Release during Hemoglobin S Denaturation. Blood 1988, 71, 1755-1758.

(4) Jiang, B.; Yao, Y.; Xie, R.; Dai, D.; Lu, W.; Chen, W.; Zhang, L. Enhanced Generation of Reactive Oxygen Species for Efficient Pollutant Elimination Catalyzed by Hemin Based on Persistent Free Radicals. Appl. Catal., B 2016, 183, 291-297.

(5) Shinjyo, N.; Kita, K. Relationship between Reactive Oxygen Species and Heme Metabolism during the Differentiation of Neuro2a Cells. Biochem. Biophys. Res. Commun. 2007, 358, 130-135.

(6) Liu, Y.; Fiskum, G.; Schubert, D. Generation of Reactive Oxygen Species by the Mitochondrial Electron Transport Chain. J. Neurochem. 2002, 80, 780-787.

(7) Simon, H.-U.; Haj-Yehia, A.; Levi-Schaffer, F. Role of Reactive Oxygen Species (ROS) in Apoptosis Induction. Apoptosis 2000, 5, 415-418.

(8) Bergamini, C.; Gambetti, S.; Dondi, A.; Cervellati, C. Oxygen, Reactive Oxygen Species and Tissue Damage. Curr. Pharm. Des. 2004, 10, 1611-1626.

(9) Conant, J. B.; Alles, C. A.; Tongberg, C. O. The Electrometric Titration of Hemin and Hematin. J. Biol. Chem. 1928, 79, 89-93.

(10) Davis, D. G.; Martin, R. F. Electrochemical Studies of Some Iron Protoporphyrin Complexes. J. Am. Chem. Soc. 1966, 88, 1365-1371.

(11) Constant, L. A.; Daws, D. G. Electrochemical Characterization of Iron Porphyrin Complexes in Aprotic Solvents. Anal. Chem. 1975, 47, 2253-2260.

(12) Bednarski, T. M.; Jordan, J. Electron-Transfer Characteristics of the Prosthetic Group of Hemoproteins. J. Am. Chem. Soc. 1967, 89, $1552-1558$.

(13) Kolpin, C. F.; Swofford, H. S. Adsorption Preconcentration for the Direct Analytical Determination of Heme. Anal. Chem. 1978, 50, 916-920.

(14) Rusling, J. F.; Brooks, M. Y. Adsorption and coupled chemical reactions in the electroreduction of ferriheme in alkaline solutions. J. Electroanal. Chem. 1984, 163, 277-296. 
(15) Bianco, P.; Haladjian, J.; Draoui, K. Electrochemistry at a pyrolytic graphite electrode. J. Electroanal. Chem. Interfacial Electrochem. 1990, 219, 305-314.

(16) Ye, J.-S.; Wen, Y.; Zhang, W. D.; Cui, H.-F.; Gan, L. M.; Xu, G. Q.; Sheu, F.-S. Application of Multi-Walled Carbon Nanotubes Functionalized with Hemin for Oxygen Detection in Neutral Solution. J. Electroanal. Chem. 2004, 562, 241-246.

(17) Su, X.; Bromberg, L.; Tan, K.-J.; Jamison, T. F.; Padhye, L. P.; Hatton, T. A. Electrochemically Mediated Reduction of Nitrosamines by Hemin-Functionalized Redox Electrodes. Environ. Sci. Technol. Lett. 2017, 4, 161-167.

(18) Chen, J.; Zhao, L.; Bai, H.; Shi, G. Electrochemical Detection of Dioxygen and Hydrogen Peroxide by Hemin Immobilized on Chemically Converted Graphene. J. Electroanal. Chem. 2011, 657, 34-38.

(19) Thirumalraj, B.; Rajkumar, C.; Chen, S.-M.; Barathi, P. Highly Stable Biomolecule Supported by Gold Nanoparticles/graphene Nano composite as a sensing platform for $\mathrm{H}_{2} \mathrm{O}_{2}$ biosensor application. $J$. Mater. Chem. B 2016, 4, 6335-6343.

(20) Wang, G.-X.; Zhou, Y.; Wang, M.; Bao, W.-J.; Wang, K.; Xia, X.H. Structure Orientation of Hemin Self-Assembly Layer Determining the Direct Electron Transfer Reaction. Chem. Commun. 2015, 51, 689-692.

(21) Sosna, M.; Fapyane, D.; Ferapontova, E. E. Reconstitution of Peroxidase Onto Hemin-Terminated Alkanethiol Self-Assembled Monolayers on Gold. J. Electroanal. Chem. 2014, 728, 18-25.

(22) Richard, M. J.; Shaffer, C. D.; Evilia, R. F. Cyclic Voltammetric and Stopped-Flow Study of Five Coordinate Hemin in NonCoordinating Solvent: Evidence for the Electron-Transfer Through the Axial Ligand. Electrochim. Acta 1982, 27, 979-983.

(23) Eftekhari, A.; Fan, Z. Ordered Mesoporous Carbon and its Applications for Electrochemical Energy Storage and Conversion. Mater. Chem. Front. 2017, 1, 1001-1027.

(24) Hartmann, M. Ordered Mesoporous Materials for Bioadsorption and Biocatalysis. Chem. Mater. 2005, 17, 4577-4593.

(25) Kumar, M. N. V. R. A Review of Chitin and Chitosan Applications. React. Funct. Polym. 2000, 46, 1-27.

(26) Gayathri, P.; Kumar, A. S. An Iron Impurity in Multiwalled Carbon Nanotube Complexes with Chitosan and Biomimics the Heme Peroxidase Function. Chem.-Eur. J. 2013, 19, 17103-17112.

(27) Nieto, J. M.; Peniche-Covas, C.; Bosque, J. D. Preparation and Characterization of a Chitosan-Fe(III) Complex. Carbohydr. Polym. 1992, 18, 221-224.

(28) Lv, X.; Weng, J. Ternary Composite of Hemin, Gold Nanoparticles and Graphene for Highly Efficient Decomposition of Hydrogen Peroxide. Sci. Rep. 2013, 3, 3285.

(29) Ratautas, D.; Ramonas, E.; Marcinkevičienè, L.; Meškys, R.; Kulys, J. Wiring Gold Nanoparticles and Redox Enzymes: A SelfSufficient Nanocatalyst for the Direct Oxidation of Carbohydrates with Molecular Oxygen. ChemCatChem 2018, 10, 971-974.

(30) Haiss, W.; Nichols, R. J.; Higgins, S. J.; Bethell, D.; Höbenreich, H.; Schiffrin, D. J. Wiring Nanoparticles with Redox Molecules. Faraday Discuss. 2004, 125, 179-194.

(31) Nellaiappan, S.; Kumar, A. S.; Nisha, S.; Pillai, K. C. In-Situ Preparation of $\mathrm{Au}(111)$ Oriented Nanoparticles Trapped Carbon Nanofiber-Chitosan Modified Electrode for Enhanced Bifunctional Electrocatalysis and Sensing of Formaldehyde and Hydrogen Peroxide in Neutral pH Solution. Electrochim. Acta 2017, 249, 227-240.

(32) Lv, X.; Weng, J. Ternary Composite of Hemin, Gold Nanoparticles and Graphen for Highly Efficient Decomposition of Hydrogen Peroxide. Sci. Rep. 2013, 3, 3285.

(33) Cheng, L.; Yan, K.; Zhang, J. Integration of Graphene-Hemin Hybrid Materials in an Electroenzymatic System for Degradation of Diclofenac. Electrochim. Acta 2016, 190, 980-987.

(34) Cabrera, A.; Celis, R.; Hermosín, M. C. Imazamox-Clay Complexes with Chitosan- and Iron(III)-Modified Smectites and Their Use in Nano Formulations. Pest Manage. Sci. 2016, 72, 12851294.
(35) Pal, S.; Ottó, B.; Etelka, T.; Hajnalka, K.; Ramóna, M. The Nature of Interactions Between Iron(III) and the Structure of the Fe(III)-Chitosan "Complex". Acta Pharm. Hung. 2007, 77, 165-175.

(36) da Silva, M. A. S.; Abreu, D. S.; Costa, L. A.; Aguiar, N. d. A.; Paulo, T. F.; Longhinotti, E.; Diógenes, I. C. N. Chitosan Film Containing an Iron Complex: Synthesis and Prospects for Heterocyclic Aromatic Amines (HAAs) Recognition. J. Agric. Food Chem. 2017, 65, 1387-1394.

(37) Zhang, M.; Huang, Z.; Zhou, G.; Zhu, L.; Feng, Y.; Lin, T.; Hou, H.; Guo, Q. A Sensitive Hydrogen Peroxide Sensor Based on a ThreeDimensional N-Doped Carbon Nanotube-Hemin Modified Electrode. Anal. Methods 2015, 7, 8439-8444.

(38) de Groot, M. T.; Merkx, M.; Wonders, A. H.; Koper, M. T. M. Electrochemical Reduction of NO by Hemin Adsorbed at Pyrolitic Graphite. J. Am. Chem. Soc. 2005, 127, 7579-7586.

(39) Cao, Y.; Si, W.; Hao, Q.; Li, Z.; Lei, W.; Xia, X.; Li, J.; Wang, F.; Liu, Y. One-Pot Fabrication of Hemin-NC Composite with Enhanced Electrocatalysis and Application to $\mathrm{H}_{2} \mathrm{O}_{2}$ Sensing. Electrochim. Acta 2008, 261, 206-213.

(40) Laviron, E. General Expression of the Linear Potential Sweep Voltammogram in the Case of Diffusion Less Electrochemical Systems. J. Electroanal. Chem. Interfacial Electrochem. 1979, 101, 1928.

(41) Cai, C.; Chen, J. Direct Electron Transfer and Bioelectrocatalysis of Hemoglobin at a Carbon Nanotube Electrode. Anal. Biochem. 2004, 325, 285-292.

(42) Zhang, R.; Wang, X.; Shiu, K.-K. Accelerated Direct Electrochemistry of Hemoglobin Based on Hemoglobin-Carbon Nanotube (Hb-CNT) Assembly. J. Colloid Interface Sci. 2007, 316, 517-522.

(43) Wei, W.; Jin, H.-H.; Zhao, G.-C. A Reagentless Nitrite Biosensor Based on Direct Electron Transfer of Hemoglobin on a Room Temperature Ionic Liquid/Carbon Nanotube-modified Electrode. Microchim. Acta 2009, 164, 167-171.

(44) Wen, Y.; Wu, H.; Chen, S.; Lu, Y.; Shen, H.; Jia, N. Direct Electrochemistry and Electrocatalysis of Hemoglobin Immobilized in Poly (Ethylene Glycol) Grafted Multi-Walled Carbon Nanotubes. Electrochim. Acta 2009, 54, 7078-7084.

(45) Zhao, H. Y.; Xu, X. X.; Zhang, J. X.; Zheng, W.; Zheng, Y. F. Carbon Nanotube-Hydroxyapatite-Hemoglobin Nano composites with High Bioelectrocatalytic Activity. Bioelectrochemistry 2010, 78, $124-129$.

(46) Kumar, A. S.; Gayathri, P.; Barathi, P.; Vijayaraghavan, R. Improved Electric Wiring of Hemoglobin with Impure-Multiwalled Carbon Nanotube/Nafion Modified Glassy Carbon Electrode and its Highly Selective Hydrogen Peroxide Biosensing. J. Phys. Chem. C 2012, 116, 23692-23703.

(47) Ma, Q.; Ai, S.; Yin, H.; Chen, Q.; Tang, T. Towards the Conception of an Amperometric Sensor of L-Tyrosine Based on Hemin/PAMAM/MWCNT Modified Glassy Carbon Electrode. Electrochim. Acta 2010, 55, 6687-6694.

(48) Zou, H. L.; Li, B. L.; Luo, H. Q.; Li, N. B. A Novel Electrochemical Biosensor Based on Hemin Functionalized Graphene Oxide Sheets For Simultaneous Determination of Ascorbic Acid, Dopamine and Uric Acid. Sens. Actuators, B 2015, 207, 535-541.

(49) Ni, Y.; Wang, P.; Song, H.; Lin, X.; Kokot, S. Electrochemical Detection of Benzo(a)pyrene and Related DNA Damage Using DNA/ Hemin/Nafion-Graphene Biosensor. Anal. Chim. Acta 2014, 821, 34-40.

(50) Jain, P. K.; Lee, K. S.; El-Sayed, I. H.; El-Sayed, M. A. Calculated Absorption and Scattering Properties of Gold Nanoparticles of Different Size, Shape, and Composition: Applications in Biological Imaging and Biomedicine. J. Phys. Chem. B 2006, 110, 7238-7248.

(51) Fidalgo-Marijuan, A.; Amayuelas, E.; Barandika, G.; Bazán, B.; Urtiaga, M.; Arriortua, M. Coordination and Crystallization Molecules: Their Interactions Affecting the Dimensionality of Metalloporphyrinic SCFs. Molecules 2015, 20, 6683-6699.

(52) Chen, H.; Tan, X.; Zhang, J.; Lu, Q.; Ou, X.; Ruo, Y.; Chen, S. An Electrogenerated Chemiluminescent Biosensor Based on a g- 
C3N4-Hemin Nanocomposite and Hollow Gold Nanoparticles for the Detection of Lactate. RSC Adv. 2014, 4, 61759-61766.

(53) Silverstein, R. M.; Bassler, G. C.; Morrill, T. C. Spectrometric Identification of Organic Compounds, 4th ed.; Wiley, 1981.

(54) Kozan, J. V. B.; Silva, R. P.; Serrano, S. H. P.; Lima, A. W. O.; Angnes, L. Biosensing Hydrogen Peroxide Utilizing Carbon Paste Electrodes Containing Peroxidases Naturally Immobilized on Coconut Fibres. Anal. Chim. Acta 2007, 591, 200-207.

(55) Feng, J.-J.; Zhao, G.; Xu, J.-J.; Chen, H.-Y. Direct Electrochemistry and Electrocatalysis of Heme Proteins Immobilized on Gold Nanoparticles Stabilized by Chitosan. Anal. Biochem. 2005, 342, 280286. 